\title{
Case study of acid fracturing of Ordovician geothermal reservoir in Taiyun area
}

\author{
Xingwu Feng ${ }^{1}$, Ruohan $\mathrm{Hu}^{2,}{ }^{,}$, Degang Xing ${ }^{1}$, Qingzhong $\mathrm{Yu}^{1}$, Jiawei $\mathrm{Chen}^{2}$, and Liping \\ Zhang $^{1}$ \\ ${ }^{1}$ Engineering Technology Research Institute of Henan Oilfield Branch company of CNOPEC, \\ Nanyang, China \\ ${ }^{2}$ Southwest Petroleum University, Chengdu, China
}

\begin{abstract}
The thermal reservoir in Taiyun area mainly consists of Ordovician and Cambrian carbonate formations. The target interval of example well contains more than $95 \%$ carbonate, being thick, argilliferous and have well-developed natural fissures and rich hot water. However, sometimes stimulation is necessary to achieve the designed water production rate. In this paper, multistage alternating injection acid fracturing technology is selected according to lithologic characteristics of geothermal reservoir. A gel acid, which is a composite of $20 \% \mathrm{HCl}+0.8 \% \mathrm{SHY} 1+2 \%$ corrosion inhibitor $+1.5 \%$ iron ion stabilizer $+1 \%$ cleanup additive, is optimized and developed by experimental tests. Its viscosity can reach $27 \mathrm{mPa} \cdot \mathrm{s}$. Then, pumping schedule of multi-stage alternate injection acid fracturing is optimized by numerical simulator of acid fracturing design. It is shown from job pressure of field sample well that resistance reduction ability of gel acid needs to be further improved. Moreover, from the analysis results of pressure decline after acid fracturing, the fluid efficiency is $42.32 \%$, net pressure is $3.3 \mathrm{MPa}$, and the dynamic fracture length is $107 \mathrm{~m}$, the maximum fracture width is $8.6 \mathrm{~mm}$ by fitting treatment pressure. The water production increase factor reaches 1.2 after acid fracturing treatment. Therefore, the acid fracturing treatment is successful.
\end{abstract}

Keywords: Thermal reservoir; carbonate formations; Acid fracturing; Gel acid.

\section{Introduction}

The development of geothermal resources is one of the main tendencies in the future. Geothermal formation in Taiyun area mainly consists of Ordovician and Cambrian carbonate, acid treatment usually is necessary to increase water production. In fact, this technique is an important and effective method for improving the production of carbonate reservoirs in petroleum industry ${ }^{[1-3]}$. Techniques such as conventional acid fracturing, deeppenetration acid fracturing and special acid fracturing have been developed ${ }^{[3]}$. In particular, the multi-stage alternate injection technology ${ }^{[4-6]}$ can significantly increase acid penetration

\footnotetext{
*Corresponding author: 201999010035@swpu.edu.cn
} 
distance of living acid, which has become the main technique for improving oil and gas production and recovery in carbonate reservoirs.

$\mathrm{Ma}^{[7]}$ introduced geothermal well acid treatment in WR95 block, during which the average treatment pressure dropped from $20 \mathrm{MPa}$ to $9.53 \mathrm{MPa}$ instantly. After acid treatment, water temperature at wellhead rose from $53^{\circ} \mathrm{C}$ to $78^{\circ} \mathrm{C}$, and water rate increased from $10.38 \mathrm{~m}^{3} / \mathrm{h}$ to $95.67 \mathrm{~m}^{3} / \mathrm{h}$. $\mathrm{Xu}^{[8]}$ summarized acid treatment of HD-39B Ordovician carbonate geothermal reservoir. Logging analysis results indicated that there are multiple aquifers in target formation, and its physical properties are poor. But water rate significantly goes up by the stimulation treatment. $\mathrm{Ji}^{[9]}$ reported that water production increased from less than $10 \mathrm{~m}^{3} / \mathrm{h}$ to $36 \mathrm{~m}^{3} / \mathrm{h}$ after acid fracturing in carbonate geothermal wells in southwestern Shandong. Yang ${ }^{[10]}$ studied the acid fracturing technology of geothermal wells in a typical area in Beijing. The concentration and volume of acid fluid, required equipment and other parameters are designed in detail. An acid fracturing scheme is determined based on numerical simulation combining with experimental results. Water production after stimulation increased from $968 \mathrm{~m}^{3} / \mathrm{d}$ to $2163 \mathrm{~m}^{3} / \mathrm{d}$, and the output water temperature increased from $43.5^{\circ} \mathrm{C}$ to $46^{\circ} \mathrm{C}$.

\section{Geothermal reservoir characteristics in Taiyun area}

The geothermal reservoir in Taiyun are ${ }^{[11]}$ is a Cambrian-Ordovician karst reservoir. The pay zone depth is about $2000 \mathrm{~m}$ and the temperature is about $80^{\circ} \mathrm{C}$.

(1) Lithological characteristics

The geothermal bedrock is mainly grey and off-white, including sandy limestone, micrite limestone, silt limestone and leopard skin limestone, etc. The fissures are mainly infilled with calcite. In general, the rocks are mainly composed of calcite and dolomite with impurities such as quartz, gypsum, and pyrite. Carbonate content is more than $95 \%$.

(2) Reservoir space characteristics

The main types of storage space are fissures, dissolved pores, and dissolved caves.

- Pores: The pores diameter is generally $10-50 \mu \mathrm{m}$ and larger pores are rarely seen, and the distribution is relatively limited.

- Fissures: They are relatively developed, which mainly includes network fissure, highangle cracks and micro-fractures. Network fractures consist of multiple groups of cross cracks intersecting each other and the width is usually less than $1 \mathrm{~mm}$. Fissures with a width larger than $1 \mathrm{~mm}$ are infilled. High-angle fractures consist of one or two groups of fractures.

- Cave: The dissolved cavities in the core are mainly developed in micrite limestone and crystalline ash, with a diameter of about $1-10 \mathrm{~cm}$.

(3) Selection of reservoir stimulation technology

Based on the adaptability of hydraulic fracturing, matrix acidizing and acid fracturing to lithology and its application experience in petroleum engineering, multistage alternating injection acid fracturing technology was selected.

\section{Experimental study on gel acid system}

In order to increase acid penetration fracture length, gel acid system was chosen because its low reaction rate on acid-rock. The concentration of hydrochloric acid and gelling agent are discussed emphatically. 


\subsection{Selection of hydrochloric acid concentration}

The dissolution ratio of rock-powder with different concentrations of hydrochloric acid is shown in figure 1 . The dissolution ratio is close to the limitation when its concentration is $20 \%$. So, $20 \% \mathrm{HCl}$ is selected based on dissolution rate with engineering experience.

\subsection{Selection of gelling agent and its concentration}

The experimental results of viscosity from 5 gelling agents (YS110, GHS, SHY1, CHW6 and $\mathrm{TH} 2$ ) are shown in figure 2. Viscosity of acid fluid increases with increasing concentration for gelling agents. The SHY1 is selected and its concentration is determined as $0.8 \%$ based on the influence on viscosity according to viscosity of 5 gelling agents.

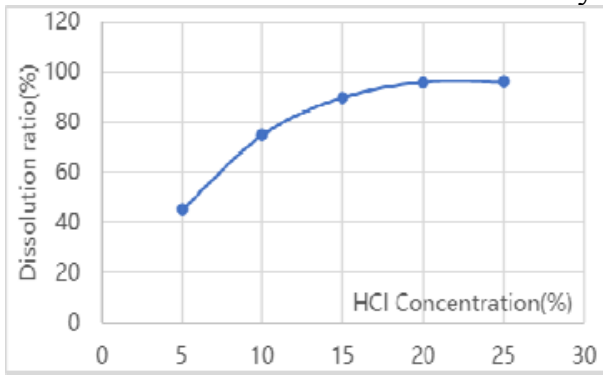

Fig. 1. Dissolution rate of $\mathrm{HCl}$ to rock-powder.

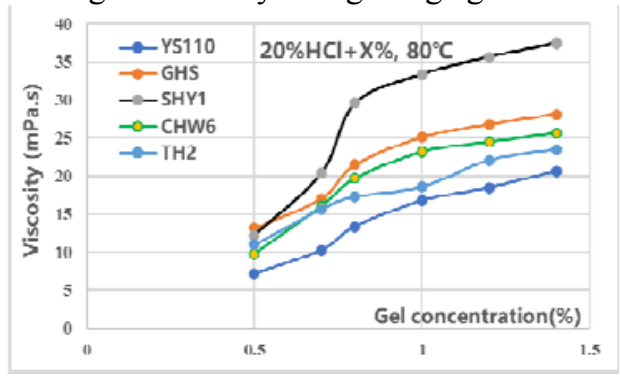

Fig. 2. Acid fluid viscosity of gel concentration.

\subsection{Acid and its main properties}

In order to meet the requirements of acid fracturing, the acid fluid system should be compatible and anti-swelling, has low surface tension and high capacity of stabilizing colloidal iron precipitation. Acid fluid system is obtained by a lot of experiments tests and evaluations:

$20 \% \mathrm{HCl}+\mathbf{0 . 8} \% \mathrm{SHY} 1+2 \%$ corrosion inhibitor $+1.5 \%$ iron ion stabilizer $+1 \%$ cleanup agent

The rheological performance of the acid fluid is tested by RS600 rheometer produced from the German HAAKE company, and it is illustrated in Fig. 3.

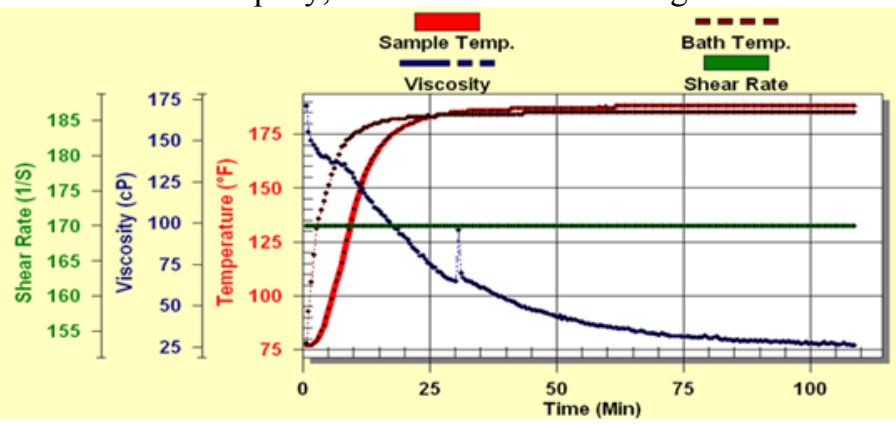

Fig. 3. Rheological performance of the acid fluid.

Fig. 3 shows that the viscosity of gelling acid can reach $27 \mathrm{mPa}$.s after continuously sheared at $80^{\circ} \mathrm{C}$ and $170 \mathrm{~s}^{-1}$ for 120 minutes, so the acid fluid has a good properties of temperature resistance and shear resistance, as well as retardative property. 


\section{Field case}

According to the development situation of natural fractures, the geothermal reservoir aquifers in Taiyun area was divided into three types. Among them, the type "I" natural fracture is the most developed, which is the most concerned aquifer and the target interval of reservoir reconstruction

The logging results of example well are illustrated in Table 1. 72-82\# geothermal zones have relatively pure lithology, large thickness and are argilliferous with natural fissures. But 75-80\# zones (i.e. 2029.3-2045.8m) are the main water-producing interval.

Table 1. Target test layer of example well.

\begin{tabular}{|c|c|c|c|}
\hline $\begin{array}{c}\text { Zone } \\
\text { number }\end{array}$ & Interval, m & Type of natural fissures & $\begin{array}{c}\text { Rank of thermal } \\
\text { abundance }\end{array}$ \\
\hline $75-80$ & $2029.3-2045.8$ & I & Main thermal layer \\
\hline 74 & $2026.7-2027.6$ & II & Secondary thermal layer \\
82 & $2064.2-2065.1$ & III & Poor thermal layer \\
\hline 72 & $2024.7-2025.5$ & & \\
\hline 13 & $2062.1-2063.0$ & & \\
\hline
\end{tabular}

\subsection{Pumping schedule of acid fracturing}

Applying simulator on multi-stage alternate acid fracturing [12-13], which contains a series of models such as temperature distribution in wellbore and fracture, propagation of fracture, acid-rock reaction, the pumping schedule of acid fracturing is optimized and it is shown in Table 2 .

Table 2. Pumping schedule of acid fracturing treatment.

\begin{tabular}{|c|c|c|c|c|}
\hline Number & stage & Rate $\left(\mathbf{m}^{\mathbf{3}} / \mathbf{m i n}\right)$ & Volume $\left(\mathbf{m}^{\mathbf{3}}\right)$ & Fluid type \\
\hline 1 & Pre-pad fluid & 2.00 & 30 & $20 \%$ Acid-Y \\
\hline 2 & Pad fluid & 5.00 & 45 & Linear glue \\
\hline 3 & Acid fluid & 4.00 & 125 & $18 \%$ Acid-Y \\
\hline 4 & Pad fluid & 5.00 & 40 & Linear glue \\
\hline 5 & Acid fluid & 4.00 & 100 & $18 \%$ Acid-Y \\
\hline 6 & Pad fluid & 5.00 & 40 & Linear glue \\
\hline 7 & Acid fluid & 4.00 & 100 & $18 \%$ Acid-Y \\
\hline 8 & Flush & 4.00 & 200 & Active water \\
\hline
\end{tabular}

\subsection{Stimulation Job analysis and fracture evaluation}

The stimulation job elapsed during 19:37-22:57 on August 8, 2016, the acid fracturing treatment curve is illustrated in Figure 4.

(1) The treatment pressure of acid injection is much higher than that of fracturing fluid injection, which indicates that the friction reduction capacity of acid fluid should be further improved.

(2) The treatment pressure converted to the same pumping rate increases first and then decreases. One of the possible reasons is that the thermal formation communicates with the nearby natural fissures zone, the other is that hydraulic fracture height is out of control to a certain extent. The real reason needs to be further verified by combining with some test methods. 
(3) The pressure steeply drops after the high-pressure point displays the effective communication of hydraulic fractures with natural fissures in thermal reservoirs.

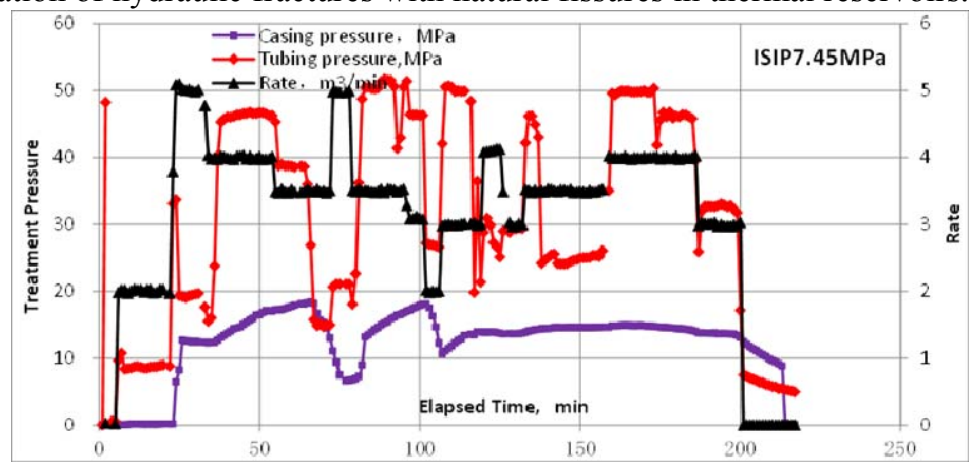

Fig. 4. Treatment pressure change curve of example well.

Applying interpretation software ${ }^{[14]}$ of fracturing pressure decline according to the pressure information after stopping pump from the sample well, it was determined that the closure pressure gradient is $13.9 \mathrm{KPa} / \mathrm{m}$, the fluid efficiency is $42.32 \%$, and the net pressure is $3.3 \mathrm{MPa}$. Then, by fitting treatment pressure, fracture geometry is displayed in Figure 5, and the dynamic fracture length is $107 \mathrm{~m}$, the maximum fracture width is $8.6 \mathrm{~mm}$.

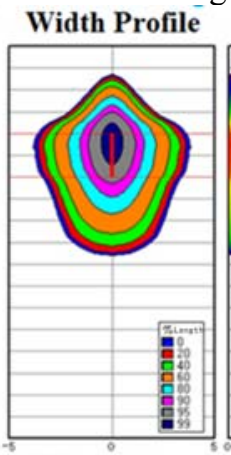

Width(mm)
Width Contours

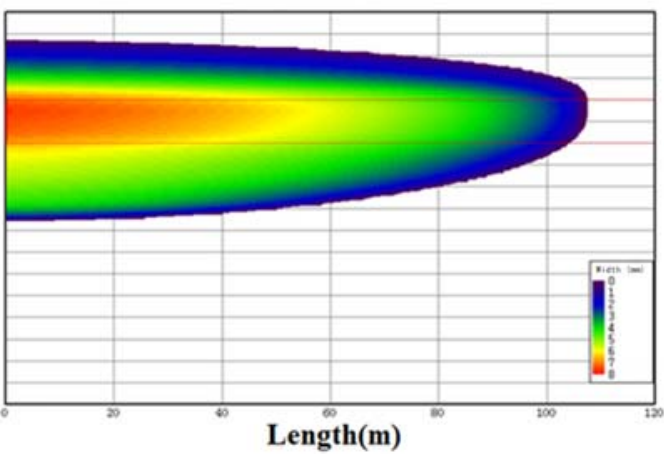

Fig. 5. Fracture geometry from acid fracturing by fitting job pressure.

\subsection{Water production after acid fracturing}

In order to improve the effect of stimulation treatment, gas lift technology is used to quickly flowback working fluid after acid fracturing treatment. Contrast of water production rate is shown in Table 3, water production after stimulation increased from $15.2 \mathrm{~m}^{3} / \mathrm{h}$ to $42.26 \mathrm{~m}^{3} / \mathrm{h}$, and the water production increase factor is a about 1.2 .

Table 3. Contrast of water production rate before and after stimulated.

\begin{tabular}{|c|c|c|c|c|c|c|}
\hline \multicolumn{3}{|c|}{$\begin{array}{l}\text { Water production before acid } \\
\text { fracturing }\end{array}$} & \multicolumn{3}{|c|}{$\begin{array}{l}\text { Water production after acid } \\
\text { fracturing }\end{array}$} & \multirow{2}{*}{$\begin{array}{l}\text { Water } \\
\text { production } \\
\text { increase } \\
\text { factor }\end{array}$} \\
\hline $\begin{array}{l}\text { Static water } \\
\text { level(m) }\end{array}$ & $\begin{array}{c}\text { Dynamic } \\
\text { water } \\
\text { level(m) }\end{array}$ & $\begin{array}{c}\text { Flow } \\
\text { rate } \\
\left(\mathbf{m}^{3} / \mathbf{h}\right)\end{array}$ & $\begin{array}{l}\text { Static water } \\
\text { level(m) }\end{array}$ & $\begin{array}{l}\text { Dynami } \\
\text { c water } \\
\text { level(m) }\end{array}$ & $\begin{array}{c}\text { Flow rate } \\
\left(\mathbf{m}^{3} / \mathbf{h}\right)\end{array}$ & \\
\hline 13.44 & -57.6 & 15.2 & -42 & -154.29 & 42.26 & 1.2 \\
\hline
\end{tabular}




\section{Conclusions}

(1) The geothermal bedrock in Taiyun area is mainly composed of limestone, and dissolved pores, caves and natural fissure are developed. The fissures in target formation are welldeveloped. The acid fracturing treatment was generally successful in this area.

(2) The gel acid was developed by lot of experiments; it is a composite of $20 \%$ hydrochloric acid $+0.8 \%$ thickener $+2 \%$ corrosion inhibitor $+1.5 \%$ iron ion stabilizer $+1 \%$ cleanup additive. The gel acid has good compatibility with geothermal reservoirs and higher viscosity of $27 \mathrm{mPa}$.s. However, its friction property needs to be further improved.

(3) According to interpretation of pressure decline after stopping pumping, the closure pressure gradient of target formation is $13.9 \mathrm{KPa} / \mathrm{m}$, the fluid efficiency is $42.32 \%$, and the net pressure is $3.3 \mathrm{MPa}$. The acid penetration fracture length is $107 \mathrm{~m}$, the maximum fracture width is $8.6 \mathrm{~mm}$ in stimulation job.

\section{References}

1. Economides M J, Nolte K G. Reservoir stimulation(Third Edition). [M] John Wiley \& Sons, Ltd, 2000

2. Leonard Kalfayan. Production enhancement with acid stimulation [M]. Penn Well Corporation, 2000

3. Li Yingchuan. Oil production engineering[M]. Petroleum Industry Press, Beijing. 2008

4. Couter A W, Crower C W et al. Alternate stages of pad fluid and acid provide improved leakoff control for fracture acidizing. SPE 6124. 1976

5. Pablo Guizada. A synopsis on completion efficiency for multi stage acid fracturing technology in tight carbonates formations. SPE 185790, 2017

6. Wang Dong. Multi-stage alternate injection closed acid fracturing technology and its application in Puguang gas field [J]. Petroleum Geology and Recovery Efficiency, 2012(6): 108-110

7. Ma Zhongping,Du Bin,Bao Wei-he. Application of acid-fracture technology in geothermal well construction[J]. Exploration Engineering(Rock \& Soil Drilling and Tunneling) , 45-47

8. $\mathrm{Xu}$ Yunpeng. Application of acidizing fracturing technology in geothermal development of carbonate strata [D]. China University of Geosciences (Beijing), 2014

9. Ji Yonghong. Application of acid Fracturing technology in geothermal well of carbonate rock in southwest of Shandong Province[J]. Site Investigation Science and Technology, 2017, (04): 62-64.

10. Yang Miao, Lin Tianyi, Liu Qing, et al. The study on geothermal acid fracturing technique in a typical area in Beijing [J]. Urban Geology, 2018, 13(4): 14-18.

11. Research on geological conditions of geothermal well for limestone heat storage[R]. Engineering Technology Research Institute of Henan Oilfield Branch company of CNOPEC, 2017

12. Wan Renpu. Technical manual of oil production (V. 9) [M]. Petroleum Industry Press, Beijing. 2008

13. Ma Shufen. Design simulation and application of multi-stage alternate injection closed acid fracturing [D]. Southwest Petroleum University, 2012

14. Mao Guoyang. Analysis of fracturing pressure decline in fractured reservoir [D]. Southwest Petroleum University, 2009. 